\title{
Optical properties of supra-nano spherical filled resin composites compared to nanofilled, nano-hybrid and micro-hybrid composites
}

\author{
María M. PEREZ $Z^{1,2}$, Cristina HITA-IGLESIAS ${ }^{1}$, Razvan GHINEA ${ }^{1,2}$, Ana. YEBRA 1 , Oscar E. PECHO ${ }^{3}$, \\ Ana M. IONESCU ${ }^{1}$, Almudena CRESPO ${ }^{1}$ and Enrique HITA ${ }^{1}$ \\ ${ }^{1}$ Department of Optics, Faculty of Science, University of Granada, Campus Fuente Nueva, Edificio Mecenas, s/n 18071, Granada, Spain \\ ${ }^{2}$ Houston Center for Biomaterials and Biomimetics, Department of Restorative Dentistry and Prosthodontics, University of Texas, School of Dentistry, \\ 7500 Cambridge St., Houston, TX 77054, USA \\ ${ }^{3}$ Post-graduate Program in Dentistry, Dental School, University of Passo Fundo, Campus I, BR285, km 171, Passo Fundo, RS, Brazil \\ Corresponding author, María M. PEREZ; E-mail: mmperez@ugr.es
}

\begin{abstract}
This study aimed to evaluate and compare the optical properties of supra-nano spherical filled resin composites and the nanofilled, nano-hybrid and microhybrid composites using the Kubelka-Munk Theory. Diffuse reflectance of samples (Shade A2) was measured against white and black backgrounds, using a spectroradiometer, using a viewing booth with D65 illuminant and d/ $0^{\circ}$ geometry. S and $\mathrm{K}$ coefficients and T were calculated using Kubelka-Munk's equations. The spectral behavior of S, K and T was similar for all dental resin composites analyzed (VAF close to 100\%), even though they were, generally, statistically different ( $p \leq 0.05$ ). The K-M T values overestimate the real value of Transmittance of the resin composites. Supra-nano spherical filled resin composites show the highest scattering and Transmittance when compared with the others materials, probably due to the shape and size of the filler. Such difference should be taken into consideration in a clinical situation to reproduce natural esthetic restorations.
\end{abstract}

Keywords: Resin composites, Scattering, Absorption, Transmittance, Supra-nano spherical filler

\section{INTRODUCTION}

Available dental resin composites, used as a restorative material, mainly vary on the resin matrix, particle size and shape, and there are many options from which to choose $^{1,2)}$. Traditionally some have been designed for bearing higher stress areas and others were improved for esthetics ${ }^{2)}$. It has been reported that mechanical ${ }^{3.5)}$ and optical properties ${ }^{5,6}$ depend highly on the concentration and particle size of the inorganic filler ${ }^{2}$.

Within each type of composite, the materials are specially distinguished by the characteristics of their reinforcing fillers and in particular their filler size. The most recent innovation in the dental composite field has been the development of the nanofilled resin composites, which contain exclusively nanoscale particles (1-100 $\mathrm{nm}$ size range $)^{1}$. Also, the formulations of microhybrid universal composites (whit filler size typically averaging about $0.4-1.0 \mu \mathrm{m}$ ) have been modified to include more nanoparticles, and possibly pre-polymerized resin fillers, similar to those found in the microfill composites, naming this new group of dental resin composites nanohybrids ${ }^{1}$.

Two resin composites with $100 \%$ supra-nano spherical filler (Estelite $\Sigma$ Quick, Estelite Omega, Tokuyama Dental, Tokyo, Japan) were developed based on the sol-gel method that both controls the diameter of fillers and changes the refractive index of the fillers ${ }^{7}$. Data from the manufacturer show that the spherical filler maintain high-gloss retention and provide life-like

Color figures can be viewed in the online issue, which is available at J-STAGE.

Received Apr 16, 2015: Accepted Oct 20, 2015

doi:10.4012/dmj.2015-126 JOI JST.JSTAGE/dmj/2015-126 opalescence by diffusing and refracting light. This allows for superior blending of the margins without generating any noticeable demarcations, creating very naturallooking restorations. Also, the manufactures show that this resin composite allows clinicians to control hue, chroma and value to achieve a natural effect. To the best of our knowledge, no information is available on optical properties of these dental resin composites and neither are available comparisons of their optical properties with other dental resin composites.

Kubelka-Munk (K-M) reflectance theory is a mathematical model describing the reflectance resulting from two-flux radiation transfer in a homogenous and uniform medium placed over an opaque backing ${ }^{8}$. The main advantage of this theory is that its absorption and scattering coefficients ( $K$ and $S$, respectively) can be easily expressed as a function of the reflectance and transmittance of the sample.

Despite its limitation, there are numerous studies in the literature which calculated the optical properties of dental tissues and materials through reflectance measurements based on the K-M reflectance theory ${ }^{9-11)}$. Recently, Mikhail et al. ${ }^{12)}$ showed that corrected K-M reflectance theory may be used to accurately quantify the optical K-M absorption and scattering coefficients for contemporary dental resin composite material.

The main objective of this study was to use the Kubelka-Munk theory to evaluate the scattering, absorption and transmittance of spherically filled supranano resin composites compared to nanofilled, nanohybrid and microhybrid composites. The null hypothesis tested was that the optical properties of supra-nano 
spherical filled resin composites did not differ from the corresponding shade of nanofilled, nano-hybrid and micro-hybrid composites.

\section{MATERIALS AND METHODS}

\section{Samples}

The properties, type, and shades of resin composites are shown in Table 1.

Standardized specimens $(10 \mathrm{~mm}$ in diameter and $1 \mathrm{~mm}$ in thickness) were made with all composite shades. Each resin composite was packed into an adaptable micrometer metal mold (Smile Line, St-Imier, Switzerland) and pressed with a mylar strip and a slide cover on the top of the specimens. All samples underwent photo-polymerization through the glass at $1,100 \mathrm{~mW} /$ $\mathrm{cm}^{2}$ for $40 \mathrm{~s}$, and on the other side after removing each specimen, with a LED curing light Bluephase ${ }^{\circledR}$ (IvoclarVivadent, Schaan, Liechtenstein). The thickness of each specimen was measured with a digital caliper (Digimatic caliper, Mitutoyo, Tokyo, Japan). Accepted thickness values were $1.00 \pm 0.01 \mathrm{~mm}$. Three disks were prepared for each shade of resin composite.

\section{Reflectance measurements}

The relative spectral radiance $\left(\mathrm{W} / \mathrm{sr} / \mathrm{m}^{2}\right)$ of dental composites samples were measured against white $\left(L^{*}=94.2, a^{*}=1.3\right.$ and $\left.b^{*}=1.7\right)$ and black $\left(L^{*}=3.1, a^{*}=0.7\right.$ and $\left.b^{*}=2.4\right) \quad 50 \times 50 \mathrm{~mm}$ ceramic tile backgrounds (Ceram, Staffordshire, UK), using a spectroradiometer (SpectraScan PR-704, Photo Research, Chatsworth, CA, USA) with $4 \%$ measurement accuracy. A saturated sucrose solution (refractive index $n=1.5$ approximately) was used as contact between the samples and the background ${ }^{12)}$.

Specimens were measured inside of a colorassessment cabinet (CAC 60, Verivide Limited, Leicester, UK) under constant illumination (light source simulating the spectral relative irradiance of the D65 CIE standard illuminant). Illuminating/measuring configuration corresponded to $\mathrm{CIE} d / 0^{\circ 13)}$. Short-term repeated measurements without replacement were performed and each specimen was measured three times. Similar to other studies ${ }^{10,14)}$ a triangular stand

Table 1 Characteristics of resin composites

\begin{tabular}{|c|c|c|c|c|}
\hline $\begin{array}{l}\text { Group } \\
\text { name }\end{array}$ & Resin composite & Shades* & $\begin{array}{l}\text { Organic matrix } \\
\text { composition** }\end{array}$ & Filler composition \\
\hline $\begin{array}{l}\text { EOEA2 } \\
\text { EODA2 }\end{array}$ & $\begin{array}{l}\text { Estelite }^{\circledR} \text { Omega } \\
\text { (Tokuyama Dental, } \\
\text { Tokyo, Japan) }\end{array}$ & $\begin{array}{l}\text { EA2 } \\
\text { DA2 }\end{array}$ & $\begin{array}{l}\text { Bis-GMA and } \\
\text { TEGDMA }\end{array}$ & $\begin{array}{l}\text { Supra-nano monodispersing spherical filler: } \mathrm{SiO}_{2}-\mathrm{ZrO}_{2} \text {. } \\
\text { Average particle size of } 0.2 \mu \mathrm{m} \text { and particle size range } \\
\text { from } 0.1 \text { to } 0.3 \mu \mathrm{m} \\
\text { ( } 78 \% \text { by vol. and } 82 \% \text { by weight) }\end{array}$ \\
\hline $\begin{array}{l}\text { ESA2 } \\
\text { ESOA2 } \\
\text { ESOPA2 }\end{array}$ & $\begin{array}{l}\text { Estelite }^{\circledR} \text { Sigma } \\
\text { Quick } \\
\text { (Tokuyama Dental) }\end{array}$ & $\begin{array}{l}\mathrm{A} 2 \\
\mathrm{OA} 2 \\
\mathrm{OPA} 2\end{array}$ & $\begin{array}{l}\text { Bis-GMA and } \\
\text { TEGDMA }\end{array}$ & $\begin{array}{l}\text { Supra-nano monodispersing spherical filler: } \mathrm{SiO}_{2}-\mathrm{ZrO}_{2} \text {. } \\
\text { Average particle size of } 0.2 \mu \mathrm{m} \text { and particle size range } \\
\text { from } 0.1 \text { to } 0.3 \mu \mathrm{m} \\
\text { ( } 71 \% \text { by vol. and } 82 \% \text { by weight) }\end{array}$ \\
\hline $\begin{array}{l}\text { FSA2E } \\
\text { FSA2B } \\
\text { FSA2D }\end{array}$ & $\begin{array}{l}\text { Filtek }^{\mathrm{TM}} \text { Supreme } \\
\text { XTE (3M ESPE, St. } \\
\text { Paul, MN, USA) }\end{array}$ & $\begin{array}{l}\mathrm{A} 2 \mathrm{E} \\
\mathrm{A} 2 \mathrm{~B} \\
\mathrm{~A} 2 \mathrm{D}\end{array}$ & $\begin{array}{l}\text { Bis-GMA, Bis- } \\
\text { EMA, UDMA, } \\
\text { TEGDMA and } \\
\text { PEGDMA }\end{array}$ & $\begin{array}{l}\text { Nanoparticle filler: Non-agglomerated/non-aggregated } \\
\text { nanosilica }(5-20 \mathrm{~nm}) \text { and zirconia }(4-11 \mathrm{~nm}) \text { fillers and } \\
\text { aggregated } \mathrm{SiO}_{2}-\mathrm{ZrO}_{2} \text { nanoclusters }(0.6-10 \mu \mathrm{m}) \\
(63.3 \% \text { by vol. and } 78.5 \% \text { by weight })\end{array}$ \\
\hline GA2 & $\begin{array}{l}\text { Grandio }^{\circledR} \mathrm{SO} \\
\text { (VOCO, Cuxhaven, } \\
\text { Germany) }\end{array}$ & $\mathrm{A} 2$ & $\begin{array}{l}\text { Bis-GMA, } \\
\text { Bis-EMA and } \\
\text { TEGDMA }\end{array}$ & $\begin{array}{l}\text { Nanohybrid filler: Functionalized } \mathrm{SiO}_{2} \text { nano-particle } \\
(20-40 \mathrm{~nm}) \text { and glass ceramics }(1 \mu \mathrm{m}) \\
(73 \% \text { by vol. and } 89 \% \text { by weight })\end{array}$ \\
\hline $\begin{array}{l}\text { HA2E } \\
\text { HA2D }\end{array}$ & $\begin{array}{l}\text { Herculite }^{\circledR} \text { XRV }^{\mathrm{TM}} \\
\text { (Kerr } \\
\text { CA, USA) }\end{array}$ & $\begin{array}{l}\mathrm{A} 2 \mathrm{E} \\
\mathrm{A} 2 \mathrm{D}\end{array}$ & $\begin{array}{l}\text { Bis-GMA, } \\
\text { TEGDMA and } \\
\text { UDMA }\end{array}$ & $\begin{array}{l}\text { Micro-hybrid filler: Aluminum silicate, Barium, } \\
\text { Zirconium }(0.04-100 \mu \mathrm{m} \text { Nanoparticles, } 50 \mathrm{~nm} \\
\text { Submicron Hybrid Filler, } 0.4 \mu \mathrm{m}) \\
\text { ( } 79 \% \text { by weight) }\end{array}$ \\
\hline $\begin{array}{l}\text { PA2E } \\
\text { PA2D }\end{array}$ & Premise $^{\mathrm{TM}}\left(\operatorname{Kerr}^{\mathrm{TM}}\right)$ & $\begin{array}{l}\mathrm{A} 2 \mathrm{E} \\
\mathrm{A} 2 \mathrm{D}\end{array}$ & $\begin{array}{l}\text { Bis-GMA and } \\
\text { TEGDMA }\end{array}$ & $\begin{array}{l}\text { Nanofiller: Trimodal filler system: prepolymerized barium } \\
\text { glass filler ( } 30 \text { to } 50 \mu \mathrm{m}) \text {, point } 4 \text { filler technology } \\
\text { (barium glass filler of } 0.4 \mu \mathrm{m} \text { average size) and } \mathrm{SiO}_{2} \\
\text { nanoparticles ( } 0.02 \mu \mathrm{m} \text { average size) } \\
\text { ( } 70 \% \text { by vol. and } 84 \% \text { by weight) }\end{array}$ \\
\hline
\end{tabular}

\footnotetext{
* B: body; D: dentin; E: enamel; O: Opaque; OPA: opalescent (Nomenclature of shades will be kept on composite groups).

** Bis-GMA: bisphenol A glycol dimethacrylate; TEGDMA: triethyleneglycol dimethacrylate; UDMA: urethane dimethacrylate; Bis-EMA: bisphenol A polyethylene glycol diether dimethacrylate
} 
was built to support the specimens and avoid specular reflection from the glossy surface. Since the field of measurement of the spectroradiometer was $1^{\circ}$, it was placed at $35 \mathrm{~cm}$, a distance which allowed the measurement of the whole specimen.

Finally, the relative spectral radiance measured for all specimens at each wavelength, in $2 \mathrm{~nm}$ steps, was converted into absolute reflectance, based on measurements of a white reflectance standard (OPTST3-C, Optopolymer, Germany)

\section{Kubelka-Munk coefficients}

The Kubelka-Munk scattering coefficient $(S)$ and absorption coefficient $(K)$ were calculated algebraically from the spectral reflectance data of each sample using the Kubelka-Munk equations as described below.

Secondary optical constants ( $a$ and $b$ ) were calculated from the experimentally obtained spectral reflectance values for the black and white background, using the following equations:

$$
\begin{aligned}
& a=\frac{1}{2} R+\left[\frac{R_{0}-R+R_{g}}{R_{0} R_{g}}\right] \\
& b=\left(a^{2}-1\right)^{1 / 2}
\end{aligned}
$$

where $R_{g}$ is the reflectance of the white background, $R_{0}$ is the reflectance of the specimen over the black background, and $R$ is the reflectance of the specimen over the white background.

The scattering coefficient $(S)$ for a unit of thickness of a specific material is defined by the following equation:

$$
S\left(\mathrm{~mm}^{-1}\right)=\frac{1}{b X} \operatorname{arctgh}\left[\frac{1-a R_{0}}{b R_{0}}\right]
$$

where $X$ is the thickness of the specimen, and $\operatorname{arctgh}$ is an inverse hyperbolic cotangent. In practical formulas, $S$ always occurs together with the thickness $\mathrm{X}$ of the specimen, that is, as the product $S X$, known as "scattering power" of the specimen.

The absorption coefficient $(K)$ and the transmittance $(T)$ are then calculated $\mathrm{as}^{8}$ :

$$
\begin{aligned}
& K\left(\mathrm{~mm}^{-1}\right)=S(a-1) \\
& T(x)=\frac{b}{a \cdot \sinh (b S X)+b \cdot \cosh (b S X)}
\end{aligned}
$$

Finally, the ratio $K / S$, proportional to the ratio of the scattering and absorption coefficients $\mu_{\mathrm{a}}$ and $\mu_{\mathrm{s}}$, was also calculated.

\section{Direct transmittance (T\%)}

For measuring the direct transmittance of light, in percentage (T\%), an ultraviolet-visible (UV/vis) spectrophotometer (Lamba 20, Perkin Elmer, Orwalk, CT, USA) was used. The calibration parameters of the spectrophotometer in scan mode included: slit of $0.5 \mathrm{~nm}$, scan speed of $240 \mathrm{~nm} / \mathrm{min}, 10 \mathrm{~nm}$ smooth. Measurements were made on the wavelength range of 400-700 $\mathrm{nm}$ with data interval of $5 \mathrm{~nm}^{15)}$.

\section{Statistical analysis}

To study the variations in scattering, absorption, and transmittance, two statistical tests were used: the Kruskal-Wallis one-way analysis of variance by ranks, which is a non-parametric method for testing average equality of measures among groups, and the MannWhitney U test. This latter test is a non-parametric test that enables the pairwise comparison of two distributions. Also, to determine the level of similarity of two different distributions, the $V A F$ (variance accounting for) coefficient with Cauchy-Schwarz inequality was used as follows ${ }^{10,15}$ :

$$
V A F=\frac{\left(\sum_{k=400}^{700} a_{k} b_{k}\right)^{2}}{\left(\sum_{k=400}^{700} a_{k}^{2}\right)\left(\sum_{k=400}^{700} b_{k}^{2}\right)}
$$

Where $a_{k}$ is the value of the absorption, scattering or transmittance at each wavelength for one measurement and $b_{k}$ is the equivalent for another measurement. The closer this coefficient gets to unity (100\%), the more similar the curves are.

\section{RESULTS}

\section{Scattering coefficient}

The spectral distributions of the K-M scattering coefficient $(S)$ for selected shades of each type of resin composites are show in Fig. 1. All shades were not included because they showed overlapped values, especially for long wavelengths. The spectral pattern of $S$ distribution showed a maximum value at approximately to $450 \mathrm{~nm}$ and decreased slightly with increasing wavelength.

Although the results showed similar spectral behavior of $S$ for all the dental resin composites studied $(94.70 \leq \mathrm{VAF} \leq 99.99 \%)$ the $S$ values of the spherically filled supra-nano resin composites were statistically different from nanofilled, nano-hybrid and micro-hybrid $(p \leq 0.05)$. Also, statistically significant differences were found among all the other types of resin composites.

\section{Absorption coefficient}

The spectral distributions of the K-M absorption coefficient $(K)$ for selected shades of each type of resin composites are presented in Fig. 2. As the case of the scattering coefficient, all shades were not included because they showed overlapped values, especially for long wavelengths. The spectral pattern of $K$ decreased with wavelength, presenting smaller values (close to zero), for long wavelengths. Micro-hybrid dental resin composites showed the lowest $K$ values for all wavelengths.

The results showed similar spectral behavior of $K$ for all the dental resin composites studied $(92.10 \leq \mathrm{VAF} \leq 99.41 \%)$. The $K$ values of the spherically filled supra-nano dental resin composites were 


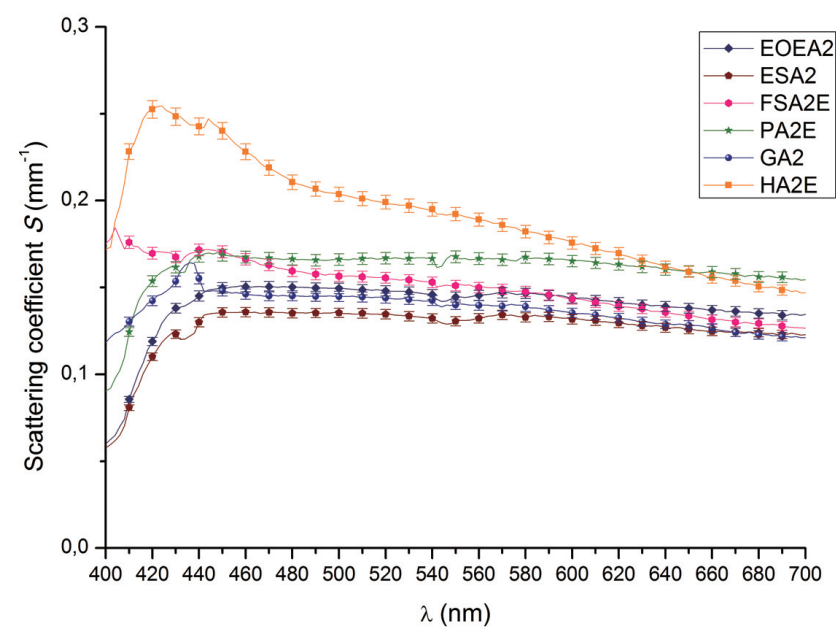

Fig. 1 Spectral distribution of the Kubelka-Munk scattering coefficient $(S)$ for supra-nano spherical filled resin composites compared whit nanofilled, nano-hybrid and micro-hybrid composites.

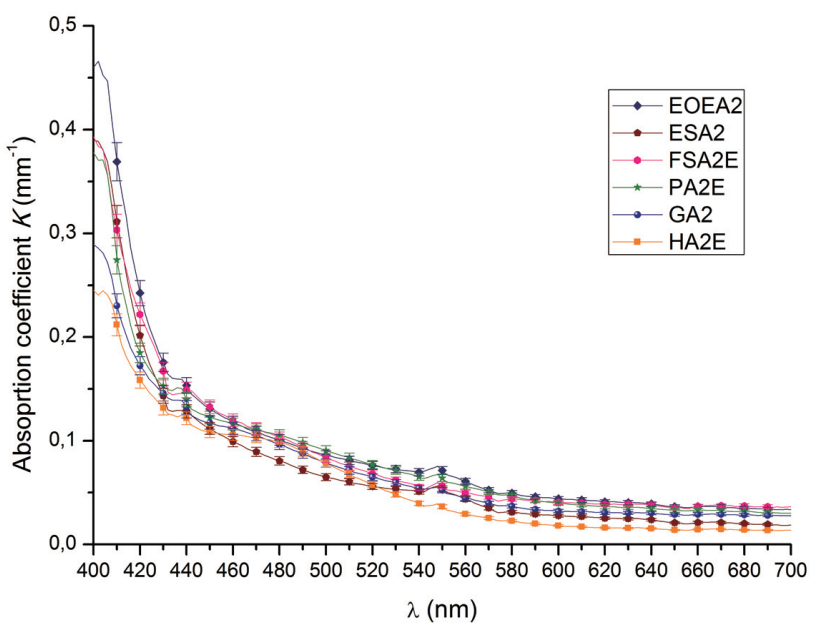

Fig. 2 Spectral distribution of the Kubelka-Munk absorption coefficient $(K)$ for supra-nano spherical filled resin composites compared whit nanofilled, nano-hybrid and micro-hybrid composites.

statistically different from nano-hybrid and microhybrid composites $(p \leq 0.05)$. No statistically significant differences were found between $K$ values for spherically filled supra-nano dental resin composites and nanofilled resin composites ( $p=0.603$ ). Also, statistically significant differences were found among all the other types of resin composites.

\section{$K / S$ ratio}

Figure 3 shows the $K / S$ ratio for selected shades of each type of resin composites. All shades were not included because they showed overlapped values, especially for long wavelengths. The values obtained for

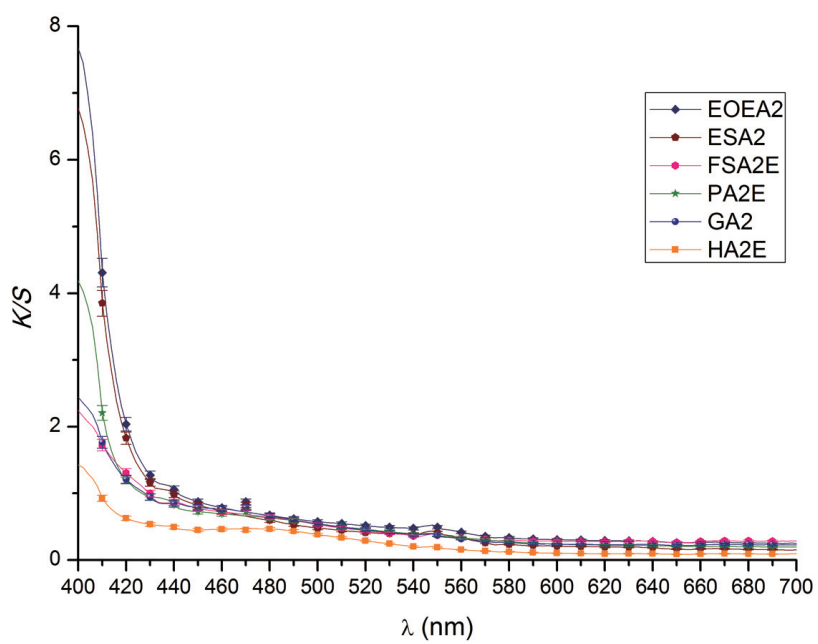

Fig. 3 Spectral distribution of $K / S$ ratio for supranano spherical filled resin composites compared whit nanofilled, nano-hybrid and micro-hybrid composites.

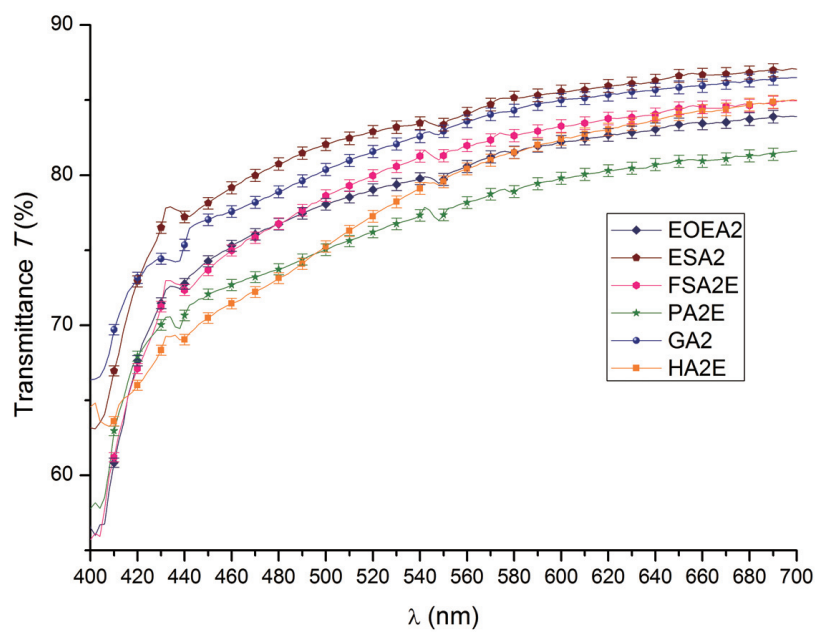

Fig. 4 Spectral distribution of Kubelka-Munk Transmittance $(T)$ for supra-nano spherical filled resin composites compared whit nanofilled, nanohybrid and micro-hybrid composites.

this ratio are higher for shorter wavelengths, decrease as the wavelength increases up to approximately $600 \mathrm{~nm}$ and remains constant for long wavelengths. According to this result, for all wavelengths higher than $440 \mathrm{~nm}$, the K-M scattering presents higher values than the absorption. For wavelengths shorter than $440 \mathrm{~nm}$, the absorption is predominant, especially for spherically filled supra-nano dental resin composites, indicating a strong prevalence of absorption over scattering for short wavelengths for this material when compared with all the other dental composites. 


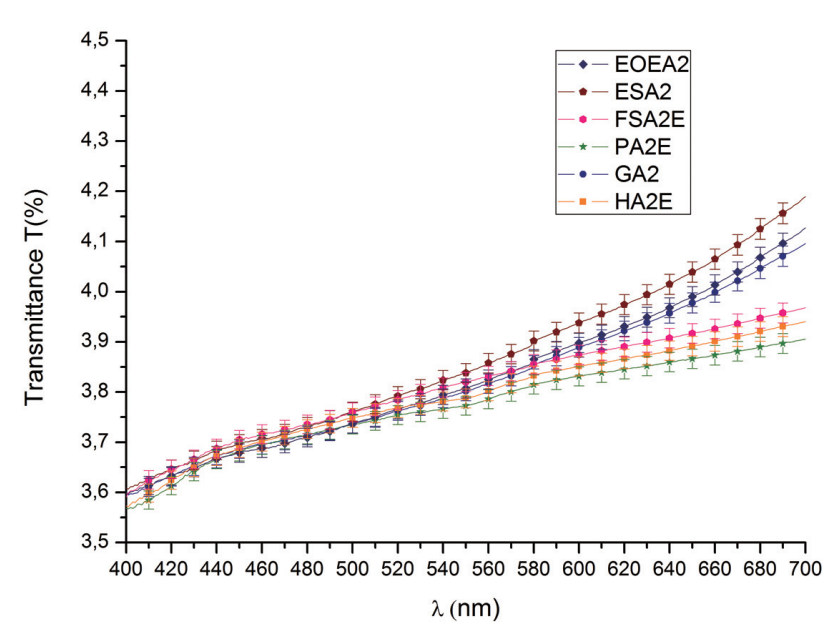

Fig. 5 Spectral distribution of Direct Transmittance (\%T) for supra-nano spherical filled resin composites compared whit nanofilled, nano-hybrid and microhybrid composites.

\section{Kubelka-Munk transmittance (T)}

Figure 4 shows the values of transmittance $(T)$ calculated according K-M equations. The spectral behavior of $T$ increased with wavelength, presenting higher values for long wavelengths. The results showed similar spectral behavior of transmittance for all the dental resin composites studied $(\mathrm{VAF} \geq 99.69 \%)$. The $T$ values of the spherically filled supra-nanodental resin composites were statistically different from nano-hybrid, nanofilled and micro-hybrid dental resin composite $(p \leq 0.05)$. Also, statistically significant differences were found among all the other types of resin composites $(p \leq 0.05)$.

\section{Direct transmittance (T\%)}

The wavelength distribution of direct transmittance $(T \%)$ for all types of resin composites are shown in Fig. 5. As the case of previous parameters, all shades were not included because they showed overlapped values. The direct transmittance values of all resin composites are dependent on the wavelength. The spectral behavior of $T$ increased with wavelength, presenting higher values for long wavelengths. The results showed similar spectral behavior of $T$ (\%) for all the dental resin composites studied $(98.10 \leq \mathrm{VAF} \leq 99.32)$ The $T(\%)$ values of the spherically filled supra-nano dental resin composites were statistically different from nano-hybrid, nanofilled and micro-hybrid dental resin composite $(p \leq 0.05)$. Also, statistically significant differences were found among all the other types of resin composites $(p \leq 0.05)$.

\section{DISCUSSION}

The physical understanding of the optical properties of dental resin composites is mandatory for their final success in dental restorative applications. Aesthetic restoration involves a visible match of the optical properties of restorative material and natural teeth. These optical properties are determined by absorption and scattering of light emerging on the surface and inside the medium. The perceived color and translucency are intimately related with light-scattering ${ }^{9,16)}$. In this work, we have employed the Kubelka-Munk theory to optically characterize the commercial spherically filled supra-nano dental resin composites and compare them with commercial nanofilled, nano-hybrid and microhybrid dental resin composites.

The optical properties of dental resin composites are determined by many factors such organix matrix composition, inorganic filler, filler content, and other additives. Arikawa et al. ${ }^{6}$ proved that shade of filler particles, as well as particle size and filler content, significantly affected the light transmittance, including light diffusion characteristics of resin composites. In this study, commercially available resin composites were used, and filler size, shape and content were different among them (Table 1).

The light diffusion through resin composites is due to multiple refraction and reflection at the resin matrixfiller particle interface. Rayleigh scattering describes the elastic scattering of light by spherical particles which are much smaller than the wavelength of light. The supra-nano spherical filled resin composites have spherical particles with an average size of $200 \mathrm{~nm}$, clearly lower than wavelengths of visible light. However, the spectral behavior of these dental resin composites (with a peak in $450 \mathrm{~nm}$ ) is not matched with the spectral distribution according Rayleigh scattering. The behavior of the scattering of these dental resin composites could be due to refractive index mismatch between the organic matrix and the filler particles and to inorganic filler size and size distribution, as suggested by some authors ${ }^{17,18)}$.

The null-hypothesis was partially rejected as supra-nano spherical filled resin composites in general showed significant differences in optical properties $(S$, $K$, and $T$ ) when compared to nanofilled, nano-hybrid and micro-hybrid composites, although all studied materials showed similar spectral behavior. Our results showed that the behavior of spectral scattering is similar between all the resin composites analyzed, but the values are significantly different with lowest values found for the supra-nano filled resin composites, and the highest values found for the micro-hybrids composites. The scattering coefficients of supra-nano spherical filled composites were significantly smaller than those of other filler-type composites, leading to larger $T$ for these resin composites, especially in shorter wavelength. These lower values of scattering, and therefore higher $T$, could be due to the shape of the filler of the supra-nano filled resin composites, opposite to the irregular filler shape found in the rest of the studied materials and to the fact that the refractive index of the filler is close to those of matrix resin of supra-nano resin composites ${ }^{19,20)}$.

A recent works ${ }^{21,22)}$ showed, in general terms, that the dental resin composites (nanocomposites and hybrid) and the human enamel exhibit a similar angular scattering behavior. Due to the similarities found 
between the spectral behavior of the supra-nano filled resin composites and the rest of the studied materials, it could be stated that this resin composite also presents a similar angular scattering behavior with the human enamel.

The $K / S$ ratio showed a predominance of scattering $(S)$ for wavelengths larger than $440 \mathrm{~nm}$ for all materials studies. This effect is greater, especially for shorter wavelength, for supra-nano spherical filled resin composites than for other materials since they present the highest absorption coefficient $(K)$ values and the lowest scattering coefficient values for these wavelengths. In dental resin composites, the absorption is produced by the organic matrix. Our results showed that no statistically significant differences were found between $K$ values for spherically filled supra-nano and nanofilled dental resin composites. According to the characteristics provided by the manufactures, the organic matrix of both materials differs (Table 1). The pigments used within the chemical compositions of the samples might be also responsible for this result. Nevertheless, further research is necessary to improve knowledge on absorption in supra-nano spherical resin composites.

Nanofilled, micro-hybrid, nano-hybrid and supranano spherical dental resin composites showed similar spectral behavior of absorption coefficient (VAF $\geq$ $92.10 \%$ ) and similar to the one found for human dentin in a previous work ${ }^{10)}$. However, the values obtained for the K-M absorption coefficient are higher than the ones found for resin composites, mostly for short and medium wavelengths. Differences in values of absorption between resin composites and human dentine were expected due to the differences in composition and structure among them.

The spectral behavior of K-M transmittance of all analyzed resin composites is similar to results reported in previous studies ${ }^{23)}$, displaying an increase of transmittance with wavelength. However, the results obtained differ especially for short wavelengths, probably due to the different methodology used (spectrophotometer and $0 / 8^{\circ}$ geometry) and, most of all, due to a higher thickness of sample $(2 \mathrm{~mm})$ in the Hosoya et $a l .{ }^{23)}$ study.

The spectral distribution of direct transmittance ( $T \%$ curves) obtained for all types of resin composites showed that the value for this parameter increases as the wavelength increased from 400 to $700 \mathrm{~nm}$ (Fig. 5). This behavior is different from K-M transmittance, which rapidly increases up to a wavelength of $450 \mathrm{~nm}$ and after it presents a soft increase for medium and large wavelengths (Fig. 4). Furthermore, the $T$ values calculated according to the K-M theory are considerably higher than the direct measured values (20 times), suggesting that the K-M theory provides overestimated values of transmittance. This result should be taken into account when using this theory in future research.

Significant differences were found for transmittance between supra-nano spherical and other resin composites. Some previous studies have shown that factors such as filler and organic matrix, refractive index, monomer type, filler type and filler content are likely to influence the light transmittance of resin composites ${ }^{24,25)}$. From Fig. 4 it can be seen that supra-nano spherical and nanohybrid specimens showed a higher light transmittance. This behavior can be explained by the lower values of scattering due to the spherical shape of the filler for this material, as shown in Fig. 1. This result could imply a greater depth of cure ${ }^{26,27)}$ and shorter curing time for this material therefore, and it should be considered when using these dental restoratives in a clinical situation.

\section{CONCLUSION}

Within the limitations of this study, it was concluded that the values of optical properties of the supra-nano spherical filler dental resin composites evaluated are different from other commercially available esthetic restorative dental materials. Such difference should be taken into consideration to reproduce natural esthetic restorations by the dental professional to achieve optimal esthetics in restorative dentistry.

\section{ACKNOWLEDGMENTS}

The authors acknowledge funding support from research projects JA TEP-1136 from Junta de Andalucía, Spain and MAT2013-43946R from the Spanish Ministry of Economy and Competitiveness. Also, the authors are grateful to Tokuyama Dental for kindly supplying some of the resin composites used in this study.

\section{REFERENCES}

1) Ferracane JL. Resin composite-state of the art. Dent Mater 2011; 27: 29-38.

2) Sakaguchi RL, Powers JM. Restorative materials-Composites and polymers. 13th ed. Philadelphia: Elsevier Mosby; 2012.

3) Li Y, Swartz ML, Phillips RW, Moore BK, Roberts TA. Effect of filler content and size on properties of composites. J Dent Res 1985; 64: 1396-1401.

4) Beun S, Glorieux T, Devaux J, Vreven J, Leloup G. Characterization of nanofilled compared to universal and microfilled composites. Dent Mater 2007; 23: 51-59.

5) Ilie N, Hicke lR. Resin composite restorative materials. Aust Dent J 2011; 56: 59-66.

6) Arikawa H, Kanie T, Fujii K, Takahashi H, Ban S. Effect of filler properties in composite resins on light transmittance characteristics and color. Dent Mater J 2007; 26: 38-44.

7) Tokuyama Dental Corporation Technical Report Tokuyama Dental, Tokyo, Japan. 2011.

8) Kubelka P. New contributions to the optics of intensely light scattering materials: Part 1. J Opt Soc Am 1948; 38: 448457.

9) Lee YK. Influence of scattering/absorption characteristics on the color of resin composites. Dent Mater 2007; 23: 124-131.

10) Pecho OE, Ghinea R, Ionescu AM, Cardona JC, Della Bona A, Perez MM. Optical behavior of dental zirconia and dentin analyzed by Kubelka-Munk theory. Dent Mater 2015; 31: 6067.

11) Ragain JC, Johnston WM. Accuracy of Kubelka-Munk reflectance theory applied to human dentin and enamel. J Dent Res 2001; 80: 449-452. 
12) Mikhail SS, Azer SS, Johnston WM. Accuracy of KubelkaMunk reflectance theory for dental resin composite material. Dent Mater 2012; 28: 729-735.

13) CIE. Colorimetry. Report No: CIE Pub No 15. Vienna: CIE Central Bureau, 2004.

14) Pérez MM, Ghinea R, Ugarte-Alván LI, Pulgar R, Paravina $\mathrm{RD}$. Color and translucency in silorane-based resin composite compared to universal and nanofilled composites. J Dent 2010; 38s: e110-e116.

15) Della Bona A, Nogueira AD, Pecho OE. Optical properties of CAD-CAM ceramic systems. J Dent 2014; 42: 1202-1209.

16) Terry DA, Geller W, Tric O, Anderson, Tourville M, Kobashigawa A. Anatomical form defines color: function, from and aesthetics. Pract Proced Aesthet Dent 2002; 14: 5967.

17) Shortall AC, Palin WM, Burtscher P. Refractive index mismatch and monomer reactivity influence composites curing depth. J Dent Res 2008; 87: 84-88.

18) $\mathrm{Yu} \mathrm{B}, \mathrm{Ahn}$ JS, Lim JK, Lee YK. Influence of $\mathrm{TiO}_{2}$ nanoparticles on the optical properties of resin composites. Dent Mater 2009; 25: 1142-1147.

19) Lee YK. Influence of filler on the difference between the transmitted and reflected colors of experimental resin composites. Dent Mater 2008; 24: 1243-1247.

20) Lim YK, Lee YK, Lim BS, Rhee SH, Yang HC. Influence of filler distribution on the color parameters of experimental resin composites. Dent Mater 2008; 24: 67-73.

21) Fernández-Oliveras A, Rubiño M, Pérez MM. Scattering anisotropy measurements in dental tissues and biomaterials. J Eur Opt Soc Rap Public 2012; 7: 12016.

22) Fernández-Oliveras A, Pecho OE, Rubiño M, Pérez MM. Measurements of scattering anisotropy in dental tissue and zirconia ceramic. Proceeding SPIE of Photonics Europe; 2012 April 16-19; Brussels, Belgium. p. 84272C-1.

23) Hosoya Y, Shiraishi T, Ando S, Miyazaki M, Garcia-Godoy F. Color characteristcs of resin composites in different color modes and geometries. J Oral Sci 2009; 51: 123-130.

24) Masotti AS, Onófrio AB, Conceiçao EN, Spohr AM. UV-vis spectrophotometric direct transmittance analysis of composite resins. Dent Mater 2007; 23: 724-730.

25) Enami N, Sjödahl M, Soderhölm KJM. How filler properties filler fraction, simple thickness and light source affect light attenuation in particulate filled resin composites. Dent Mater 2005; 21: 721-730.

26) dos Santos GB, Monte Alto RB, Sampaio Filho HR, da Silva EM, Fellows CE. Light transmission on dental resin composites. Dent Mater 2008; 24: 571-576.

27) Kawaguchi M, Fukushima T, Miyazaki K. The relationship between cure depth and transmission coefficient of visiblelight-actived resin composites. J Dent Res 1994; 73: 516-521. 